\title{
Nitric Oxide Synthase Modulates the Antihyperalgesic Effect of the NMDA Receptor Antagonist MK-801 on Carrageenan- Induced Inflammatory Pain in Rats
}

\author{
Dragana P. Srebro, ${ }^{1}$ Sonja M. Vucković, ${ }^{1}$ Katarina R. Savic Vujovic ${ }^{1}$ and \\ Milica S. Prostran ${ }^{1}$ \\ ${ }^{1}$ Department of Pharmacology, Clinical Pharmacology and Toxicology, Faculty of Medicine, University of \\ Belgrade, Belgrade, Serbia
}

\begin{abstract}
The $\mathrm{N}$-methyl-D-aspartate (NMDA) receptor, an ionotropic glutamate receptor, may play a significant role in the development and maintenance of an inflammatory pain. Activation of NMDA receptors may cause nitric oxide (NO) release through activation of $\mathrm{NO}$ synthase (NOS). MK-801, a noncompetitive NMDA receptor antagonist is commonly used as a neuropharmacological tool. The interaction between MK-801 and NOS in the inflammatory pain has not been evaluated before. We investigated whether MK-801 affects inflammatory pain and whether NOS modulates the effect of MK-801. Carrageenan-induced hyperalgesia was evaluated by measuring the withdrawal response to mechanical stimuli, using an electronic version of the von Frey anesthesiometer in Wistar rats. MK-801 given subcutaneously $(0.5-20 \mu \mathrm{g} / \mathrm{kg})$ or intraplantarly ( 0.1 and $0.15 \mu \mathrm{g} / \mathrm{paw}$ ) significantly reduced mechanical hyperalgesia. Intraplantarly given MK-801 exerted a local antihyperalgesic effect, because when applied to the contralateral side it did not reduce mechanical sensitivity in the ipsilateral side. N-nitro-L-arginine methyl ester hydrochloride ( 5 and $10 \mathrm{mg} / \mathrm{kg}$ ), a non-selective NOS inhibitor, significantly reduced the effects of MK-801. N- $\omega$-Propyl-L-arginine hydrochloride $(0.5-2 \mathrm{mg} / \mathrm{kg})$, a selective inhibitor of neuronal NOS, increased the antihyperalgesic effect of MK-801, whereas S-methylisothiourea $(5-15 \mu \mathrm{g} / \mathrm{kg})$, a selective inhibitor of inducible NOS, lowered the antihyperalgesic effect of MK-801. Importantly, each NOS inhibitor given alone did not affect carrageenaninduced hyperalgesia. In conclusion, MK-801 is effective against inflammatory pain and its antihyperalgesic effect is modulated in a different ways by NOS, being enhanced by a neuronal NOS inhibitor but reduced by an inducible NOS inhibitor.
\end{abstract}

Keywords: carrageenan; mechanical hyperalgesia; MK-801; nitric oxide; rat Tohoku J. Exp. Med., 2014 December, 234 (4), 287-293. C 2014 Tohoku University Medical Press

\section{Introduction}

MK-801 (dizocilpine) acts as a non-competitive antagonist of $N$-Methyl-D-aspartate (NMDA) receptors and blocks NMDA-induced currents in a voltage-dependent manner, preventing the influx of calcium ions through the channel (Kovacic and Somanathan 2010). MK-801 is highaffinity compound and is useful as a pharmacological tool to explore NMDA receptor function. As a research tool, MK-801 has a significant impact on the elucidation of the pathogenesis of many diseases, including psychiatric and neurodegenerative disease, and consequently a significant impact in the search for new therapeutic approaches (Boyce et al. 1999; Suetake-Koga et al. 2006). Preclinical results suggest that MK-801 has analgesic, antioxidant, neuroprotective action and has many effects in learning and memory. MK-801 is a potent anticonvulsant and dissociative anes- thetic; however, MK-801 is not used clinically because it has been shown to promote the development of brain lesions in rats (Olney et al. 1989). It is well known for its neuroprotective effect in animal models of stroke, trauma, Parkinsonism and Alzheimer's disease (Jeong et al. 2010; Im et al. 2012; Wang et al. 2014). In rats, MK-801 induces a characteristic behavioral syndrome with ataxia, stereotypic behavior and hyperlocomotion (Suetake-Koga et al. 2006). Also, injection of rats with (+)-MK-801 has been successfully employed in experimental models of both the positive and negative symptoms of schizophrenia (Rung et al. 2005). Its analgesic effect is recognized in neuropathic (Begon et al. 2000) and inflammatory pain (Hama et al. 2003; Andreasen et al. 2013), after systemic (Ren et al. 1992a, b; Berrino et al. 2003; Chen et al. 2010) or local applications (Jackson et al. 1995; Davidson et al. 1997; Du et al. 2003). However, the mechanism of MK-801 action in

Received August 7, 2014; revised and accepted November 18, 2014. Published online December 6, 2014; doi: 10.1620/tjem.234.287.

Correspondence: Dragana P. Srebro, M.D., Department of Pharmacology, Clinical Pharmacology and Toxicology, Faculty of Medicine,

University of Belgrade, Dr Subotića-starijeg 1, P.O. Box 38, 11129 Belgrade, Serbia.

e-mail: srebrodragana1@gmail.com 
inflammatory pain remains to be elucidated.

Activation of NMDA receptors is involved in the induction and maintenance of sensitization processes that characterize inflammatory pain states (Ren et al. 1992b; Lawand et al. 2000; Petrenko et al. 2003; Du et al. 2003). As a consequence of the activation of NMDA receptors by excitatory amino acids, the resulting increase in intracellular calcium leads to nitric oxide (NO) production (Freire et al. 2009). NO is involved in many processes in the central and peripheral nervous systems where it acts as a neuromodulator, a neuroprotective and a neurotoxic agent (Calabrese et al. 2007). Apart from its physiological functions, such as the control of sleep, appetite, body temperature and neurosecretion, $\mathrm{NO}$ is noxious when produced in excess as a result of inducible NO synthase (iNOS) induction, and it is involved in neuronal degeneration after traumatic brain injury (Freire et al. 2012), and also in the development of neurodegenerative disorders such as Alzheimer's and Parkinson's diseases (Calabrese et al. 2007). A number of studies suggest that the activation of calcium-dependent NO synthase (NOS) and the subsequent production of NO triggered by glutamate through the activation of NMDA receptors play an important role in central and peripheral modulation of nociception (Kawamata and Omote 1999; Tanabe et al. 2009). We have recently reported that in rats with carrageenan-induced inflammation, magnesium sulfate, a non-competitive NMDA receptor antagonist, reduced mechanical hyperalgesia, and that NO was involved in the mechanism of action (Srebro et al. 2014). It is therefore possible that MK-801, an antagonist of NMDA receptors, influences NO production.

The present study had two objectives. The first was to determine whether MK-801 affects the inflammatory pain using the model of carrageenan-induced mechanical hyperalgesia. The second was to determine whether NOS modulates the effect of MK-801. We assessed the effects of N-nitro-L-arginine methyl ester hydrochloride (L-NAME), a non-selective NOS inhibitor, N- $\omega$-Propyl-L-arginine hydrochloride (L-NPA), a selective inhibitor of neuronal NOS (nNOS), and S-methylisothiourea (SMT), a selective inhibitor of iNOS, on the effect of MK-801 on nociception.

\section{Materials and Methods}

Animals

Adult, male Wistar rats $(n=156)$, weighing 230-290 g, were used. The use of laboratory animals was approved by the Ethics Committee for Animal Research and Welfare of the Faculty of Medicine, University of Belgrade (permit $N^{\circ}$ 4946/2). All experiments were approved by the Ethical Council for the Protection of Experimental Animals of the Ministry of Agriculture, Forestry and Water Management of the Republic of Serbia, which operates in accordance with the Animal Welfare Law of the Republic of Serbia, and IASP (International Association for the Study of Pain) Guidelines for the Use of Animals in Research. The animals were housed in groups of three in cages $(42.5 \times 27 \times 19 \mathrm{~cm})$ under standard conditions of temperature $\left(22 \pm 1^{\circ} \mathrm{C}\right)$, relative humidity $(60 \%)$ and a $12 / 12$ h light/dark cycle. Food and water were freely available, except during the experimental procedures. The animals were fed a standard rat pellet feed obtained from the Veterinary Institute, Subotica, Serbia. Prior to each experiment, the animals were habituated to handling and experimental procedures for at least three consecutive days. Rats were randomized into experimental groups consisting of 6 animals per group. The experiments were conducted by the same experimenter on consecutive days under constant laboratory conditions (temperature, light, humidity, quiet) and always at the same time of day (between 8:00 and 16:00 h) to avoid diurnal variation in the behavioral tests. Each animal was used only once and was killed at the end of the experiments with an intraperitoneal injection of sodium thiopental $(200 \mathrm{mg} / \mathrm{kg})$.

Experimental protocol for carrageenan-induced peripheral inflammation and the electronic pressure-meter test

The animals were acclimatized $60 \mathrm{~min}$ before control measurements of the paw withdrawal threshold (PWT) to mechanical stimuli. At all times during the experiment, the rats were not restrained and were kept in individual Plexiglas boxes, raised on a special steel rack (Mesh Stand for mice and rats, IITC Life Science, Woodland Hills, USA). After control measurements and a break of $30 \mathrm{~min}$, peripheral hyperalgesia was induced by intraplantar (i.pl.) injection of $0.1 \mathrm{ml}$ of carrageenan $(0.5 \%)$ into the right hind paw. Hind paw mechanical thresholds were assessed by measuring the withdrawal response to von Frey filament stimulation, using an electronic version of the von Frey test (electronic von Frey Anesthesiometer, Model 2390, IITC Life Science, Woodland Hills, USA). The von Frey filament was applied to the plantar surface of the tested paw until paw withdrawal occurred, provoking a flexion reflex. The electronic pressure meter automatically recorded the intensity of the stimulus when the paw was withdrawn. Before paw stimulation, the animals should be quiet, without exploratory or toilet movements, and not resting on the paws. Measurements were performed three to five times in each rat, and the average of the middle three values was calculated. The intensity of hyperalgesia was quantified as the difference in pressures [d (g)] applied before and after injection of carrageenan (control d) or before and after injection of carrageenan plus drugs (test d). Analgesic activity (AA \%) for each rat was calculated according to the formula (Srebro et al. 2014): \%AA $=($ control group average $d-$ test $d) /($ control group average $d) \times 100$. If tested $d$ values were greater than the control group average $\mathrm{d}$, a value of $0 \% \mathrm{AA}$ was assigned. When percent inhibition $(\% \mathrm{I})$ of the antinociceptive effect with NOS inhibitors was examined the pretreatment was expressed as follows: $\% \mathrm{I}=100-$ [\%AA (in the presence of NOS inhibitor and MK- 801 ) $\%$ AA (in the presence of MK-801)] $\times 100$. The onset and cessation of the effect of the treatment were defined as the first and last time points, respectively, when a statistically significant difference between the treated and control groups (carrageenan/saline) occurred for the PWT. To examine whether the tested inhibitors have any effect on mechanical PWT in carrageenan-treated rats, the same doses of each inhibitors were administered to a separate group of rats. In this case, the rats were received the corresponding volumes of saline, instead of MK-801. The hind PWT to mechanical stimuli was measured at 0 , $0.25,0.5,1,2,3,4,5$ and $6 \mathrm{~h}$ after intraplantar injection of carrageenan.

Drugs and drug administration

MK-801 ((+)-MK-801 hydrogen maleate; Sigma-Aldrich, St. 
Louis, MO, USA), N-nitro-L-arginine methyl ester hydrochloride, (L-NAME; Sigma-Aldrich, St. Louis, MO, USA), N- $\omega$-Propyl-Larginine hydrochloride (L-NPA, Tocris Bioscience, Bristol, UK) S-methylisothiourea (SMT, Tocris Bioscience, Bristol, Great Britain), and $\lambda$-carrageenan (Sigma-Aldrich, St. Louis, MO, USA) were dissolved in saline and injected subcutaneously (MK-801) or intraperitoneally (L-NAME, L-NPA, SMT) at a final volume of $2 \mathrm{ml} / \mathrm{kg}$, and intraplantarly (carrageenan and MK-801) at a final volume of $0.1 \mathrm{ml}$ per paw.

MK-801 (0.5-20 $\mu \mathrm{g} / \mathrm{kg})$ was administered subcutaneously (s.c.) $5 \mathrm{~min}$ before the injection of carrageenan. Local peripheral effects were evaluated by intraplantar co-administration of carrageenan and MK-801 ( 0.1 and $0.15 \mu \mathrm{g} / \mathrm{paw})$. To exclude systemic effects, the same doses of MK-801 were administered to the contralateral paw. L-NAME (5 and $10 \mathrm{mg} / \mathrm{kg}$ ), L-NPA $(0.5,1$ and $2 \mathrm{mg} / \mathrm{kg}$ ) or SMT (5, 10 and $15 \mu \mathrm{g} / \mathrm{kg}$ ) was administered intraperitoneally (i.p.) $10 \mathrm{~min}$ before MK-801.

\section{Statistical analysis}

The data are presented as mean differences in pressure $\mathrm{d}(\mathrm{g}) \pm$ standard errors of the mean (SEM) obtained in six rats. A difference between the corresponding means in the PWT was verified by Student's $t$-test or analysis of variance (One-Way ANOVA), followed by Tukey's HSD post hoc test. A $p$ value lower than 0.05 was considered statistically significant.

\section{Results}

Carrageenan-induced mechanical hyperalgesia

As expected, the carrageenan injection induced inflammation of the injected hind paw, as evidenced by edema and erythema. After carrageenan injection, the PWT to mechanical stimuli was maximally reduced by $34.9 \pm 1$ (Fig. 1), $35.1 \pm 1.9$ (Fig. 2), $35.8 \pm 1.1$ (Fig. 3), $31.1 \pm 0.9$
(Fig. 4) and $33.0 \pm 1.6 \mathrm{~g}$ (Fig. 5), at time points $2-4 \mathrm{~h}$. The PWT did not change for the contralateral paw, indicating the absence of secondary hyperalgesia (not shown). There were no significant differences in the baseline (before carrageenan administration) and mechanical thresholds between the groups tested (ranged between $48.8 \pm 0.8$ and $52 \pm 0.6 \mathrm{~g}$, not shown).

\section{Systemic effects of MK-801 on the mechanical PWT}

Subcutaneously administered MK-801 (0.5-20 $\mu \mathrm{g} / \mathrm{kg})$ reduced hyperalgesia in a dose-dependent manner. About $30 \mathrm{~min}$ after injections of $0.5,5$ and $20 \mu \mathrm{g} / \mathrm{kg}$, the hyperalgesia was significantly $(p<0.05)$ reduced by $40.3 \pm 8.4$, $48.5 \pm 11.4$ and $79.1 \pm 22 \%$, respectively (Fig. 1). The effects peaked at $0.5 \mathrm{~h}$ and persisted for the next 3 to $5 \mathrm{~h}$. Only the highest dose tested $(20 \mu \mathrm{g} / \mathrm{kg})$ caused a slight increase of the PWT (the difference ranged from $2.7 \pm 2.8$ to $9 \pm 5.5 \mathrm{~g} ; p>0.05$ as compared to the values obtained after saline administration; Student's $t$-test for independent samples) on the contralateral (non-inflamed) paw in the first two hours after injection. This result suggested disruption in the behavioral assessment of the nociceptive sensitivity in rats (not shown).

\section{Local peripheral effects of MK-801 on the mechanical PWT}

Fig. 2 shows that MK-801 at a dose of $0.1 \mu \mathrm{g} / \mathrm{paw}$, when co-injected with carrageenan into the right hind paw, reduced the PWT by $20.7 \pm 3.6 \%$ at the $2 \mathrm{~h}$ time point. MK-801 at a dose of $0.15 \mu \mathrm{g} / \mathrm{paw}$ significantly $(p<0.05)$ reduced carrageenan hyperalgesia by $34.6 \pm 8.8$ and $28.5 \pm$ $5.2 \%$ at 2 and $3 \mathrm{~h}$, respectively. The same dose injected into the contralateral (non-inflamed) paw had no influence
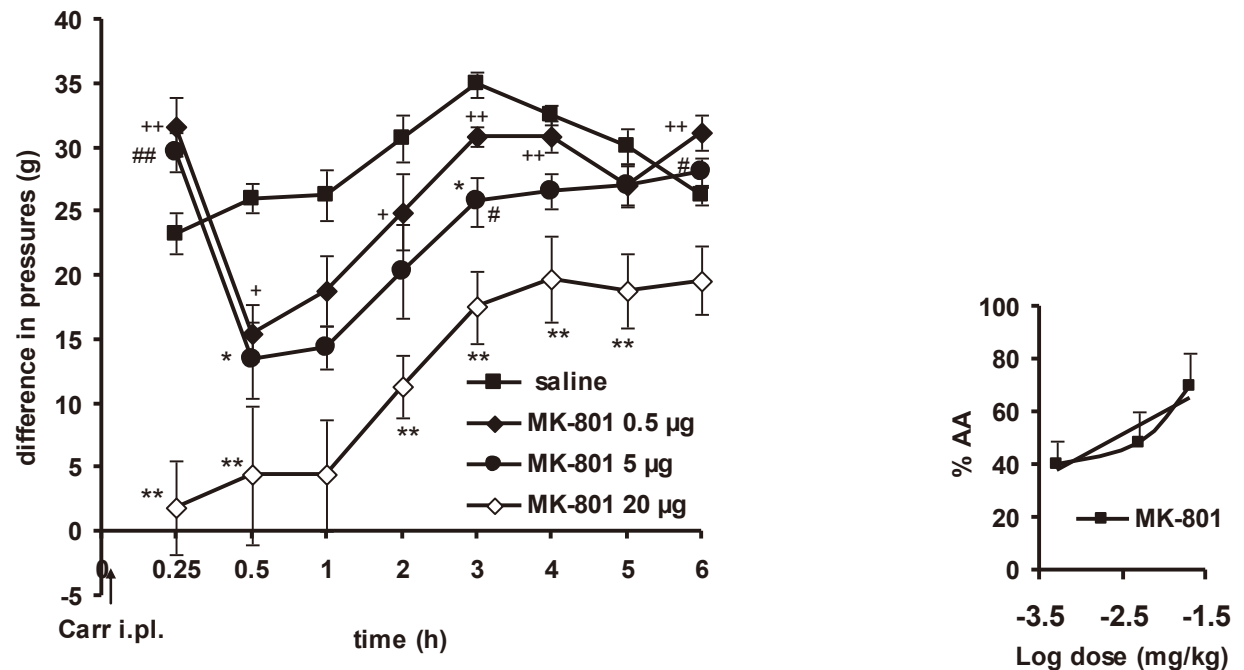

Fig. 1. Systemic effect of MK-801 on mechanical hyperalgesia. The abscissa presents the time after the injection of carrageenan (designated as 0 minute): 0.25 means quarter of an hour, 0.5 means half an hour, and 1 to 6 denotes hour(s). The ordinate presents the difference in pressures $(\mathrm{g})$ applied to the plantar surface of the paw before and after injection of drugs. Statistical significance $\left({ }^{*} p<0.05,{ }^{* *} p<0.01\right)$ was determined by comparison with the curve for saline. Statistical significance was found between MK-801 0.5 and MK-801 $20\left({ }^{+} p<0.05,{ }^{++} p<0.01\right)$ and between MK-801 5 and

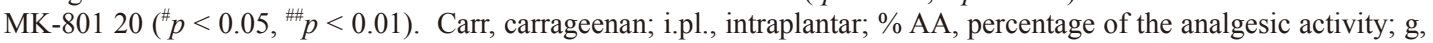
gram. 


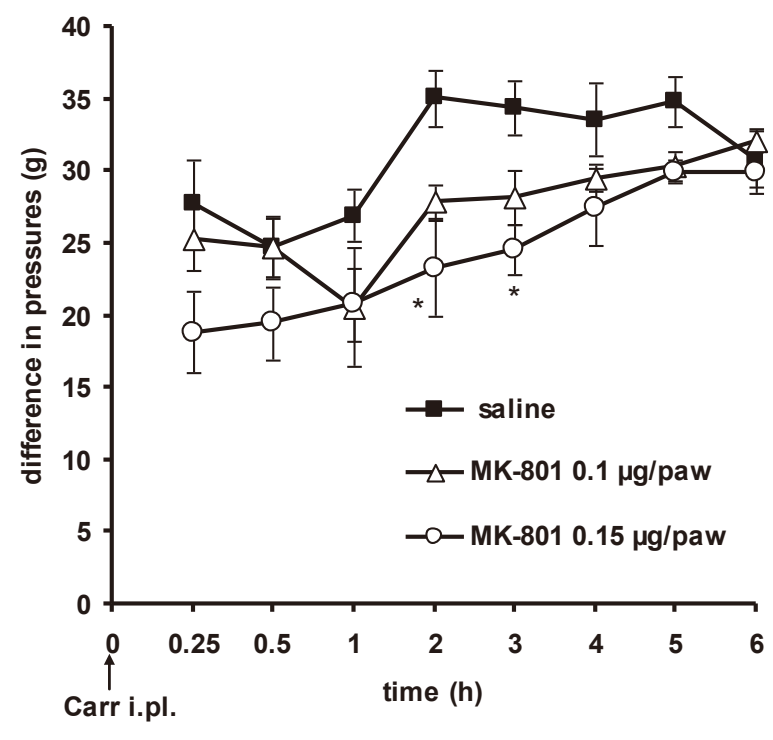

Fig. 2. Local effect of MK-801 on mechanical hyperalgesia. Statistical significance $\left({ }^{*} p<0.05\right)$ was determined by comparison with the curve for saline. Carr, carrageenan; i.pl., intraplantar; g, gram.

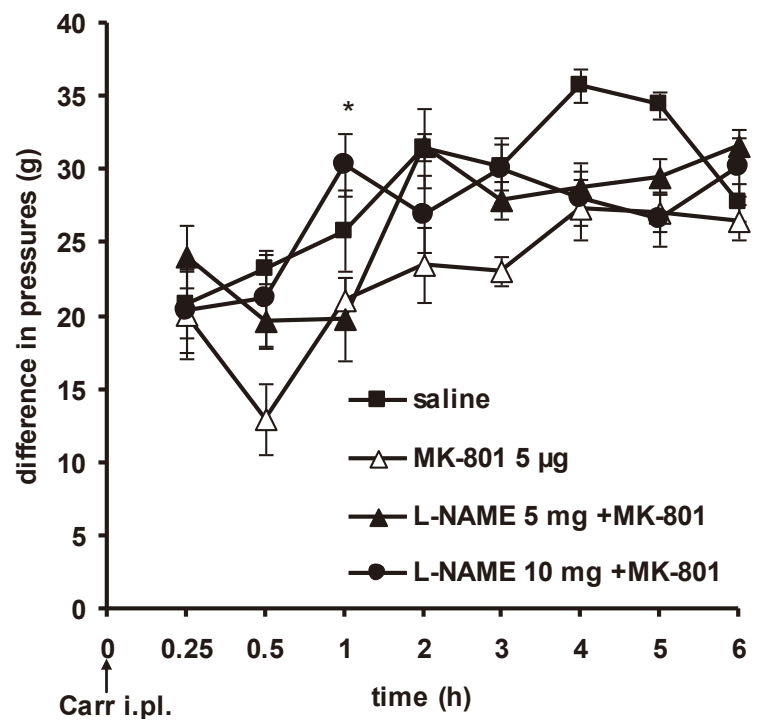

Fig. 3. The influence of L-NAME on the antihyperalgesic effect of MK-801. Statistical significance was found between L-NAME $10+$ MK-801 and MK-801 $\left({ }^{*} p<\right.$ 0.05). Carr, carrageenan; i.pl., intraplantar; g, gram.

on carrageenan-induced hyperalgesia (not shown).

The influence of L-NAME on the antihyperalgesic effect of $M K-801$ in carrageenan-treated rats

L-NAME at doses of 5 and $10 \mathrm{mg} / \mathrm{kg}$ abolished the antihyperalgesic effect of MK-801 $(5 \mu \mathrm{g} / \mathrm{kg})$ at the 2 and 1 h $(p<0.05)$ time points, respectively (Fig. 3). When applied alone, L-NAME (5 and $10 \mathrm{mg} / \mathrm{kg}$ ) did not have any influence on carrageenan hyperalgesia (not shown).

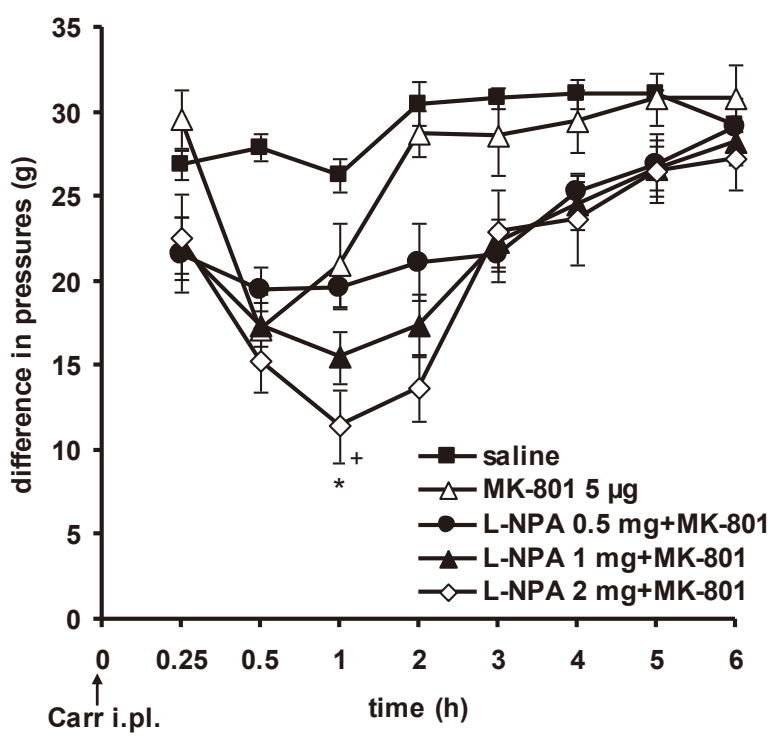

Fig. 4. The influence of L-NPA on the antihyperalgesic effect of MK-801. Statistical significance was found between L-NPA $2+$ MK-801 and MK-801 $(* p<0.01)$ and between L-NPA $2+$ MK-801 and L-NPA $0.5+$ MK-801 $\left({ }^{+} p<0.05\right)$. Carr, carrageenan; i.pl., intraplantar; g, gram.

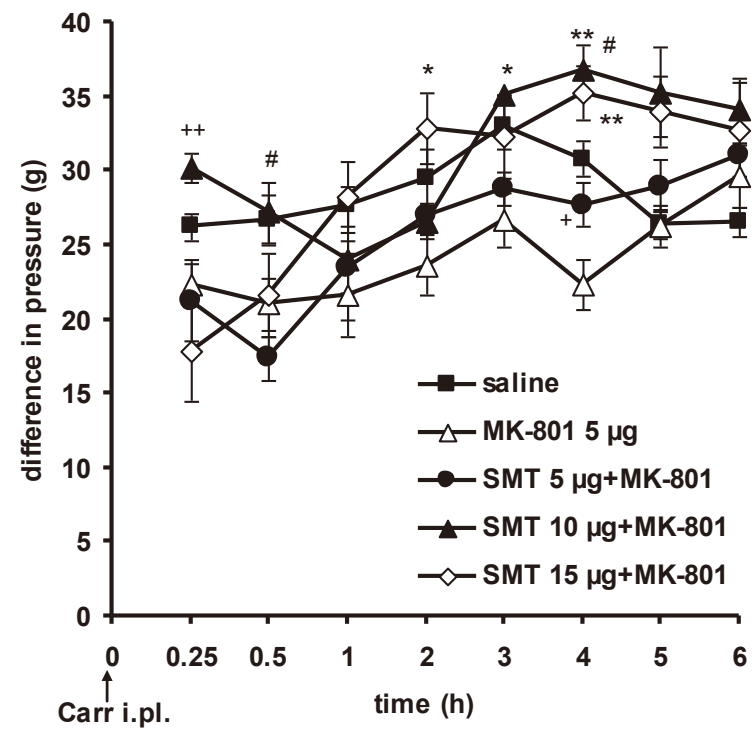

Fig. 5. The influence of SMT on the antihyperalgesic effect of MK-801. Statistical significance was found between SMT 10 or $15+$ MK-801 and MK-801 $\left({ }^{*} p<0.05, * * p<\right.$ $0.01)$, SMT 5 or $10+$ MK-801 and SMT $15+$ MK-801 $\left({ }^{+} p<0.05,{ }^{++} p<0.01\right)$ and between SMT $5+$ MK-801 and SMT $10+$ MK-801 $\left({ }^{\#} p<0.05\right)$. Carr, carrageenan; i.pl., intraplantar; g, gram.

The influence of L-NPA or SMT on the antihyperalgesic effect of MK-801 in carrageenan-treated rats

L-NPA, a selective inhibitor of nNOS, at dose of $2 \mathrm{mg} /$ $\mathrm{kg}$ significantly $(p<0.05)$ increased the antihyperalgesic effect of MK-801 $(5 \mu \mathrm{g} / \mathrm{kg})$ at time point $1 \mathrm{~h}$, while lower doses of 1 and $0.5 \mathrm{mg} / \mathrm{kg}$ had weak or no effect on the antihyperalgesic effect of MK-801 (Fig. 4). SMT, a potent and 
selective inhibitor of iNOS, at doses of 5,10 and $15 \mu \mathrm{g} / \mathrm{kg}$ reduced $(p<0.05)$ the effect of MK-801 in a dose-dependent manner (Fig. 5). When given alone, L-NPA ( $2 \mathrm{mg} / \mathrm{kg}$ ) or SMT $(15 \mu \mathrm{g} / \mathrm{kg})$ did not have any influence on carrageenan hyperalgesia (not shown).

\section{Discussion}

The present study showed that systemic pretreatment with MK-801 (0.5-20 $\mu \mathrm{g} / \mathrm{kg}$, s.c.) or local intraplantar administration of MK-801 (0.1 and $0.15 \mu \mathrm{g} / \mathrm{paw})$ resulted in a dose-dependent increase in the mechanical threshold in carrageenan-induced inflammatory pain in rats. Using the same model of pain several authors have demonstrated that MK-801 in a dose-dependent manner blocks the development of thermal hyperalgesia after systemic (Ren et al. 1992a; Chen et al. 2010) or local (Jackson et al. 1995) administrations, as well as mechanical hyperalgesia in arthritis pain (Cavalcante et al. 2013). In our study, we achieved an analgesic effect with smaller doses of MK-801 $(0.5-20 \mu \mathrm{g} / \mathrm{kg}$, s.c.). This is in contrast to previous authors who obtained the same effect with higher doses of MK-801 (with $0.1-2 \mathrm{mg} / \mathrm{kg}$ i.p., and with $10 \mathrm{nmol}=3 \mu \mathrm{g}$ i.pl.). The doses of MK-801 that produced the analgesic effect in the present study, according to literature data $(0.025,0.05$ and $0.1 \mathrm{mg} / \mathrm{kg}$ ), did not affect locomotor activity (Carey et al. 1998; Yonehara et al. 2002). This is supported by our finding that MK-801 did not modify the mechanical threshold on the contralateral (non-inflamed) paw, except for a weak effect that was observed with the highest dose tested. This result suggests that MK-801 did not disturb the behavioral assessment of the nociceptive sensitivity in rats. Similar analgesic effects of MK- 801 have been reported in the other models of inflammatory pain. Systemic administration of MK-801 has been reported to suppress formalin-induced tonic pain (Yamamoto and Yaksh 1992; Vaccarino et al. 1993; Berrino et al. 2003; Gong et al. 2011). MK-801 prevented the late phase of formalin pain, but was not effective in reversing of the established pain state (Yamamoto and Yaksh 1992; Vaccarino et al. 1993). The peak of the effect of MK-801 observed in our study is in the accordance with the literature data, in which MK-801 after i.p. administration to rats reached maximal concentrations in plasma and brain within 10 to $30 \mathrm{~min}$ of injection $(2 \mathrm{mg} / \mathrm{kg}$ ) (Vezzani et al. 1989). In addition, local intraplantar administration of MK-801 attenuated the late phase of formalin-induced pain (Davidson et al. 1997) and it could reverse complete Freund's adjuvant (CFA)-induced mechanical sensitivity (Du et al. 2003). Under similar conditions of inflammatory pain, the antinociceptive activity of ketamine, also a NMDA antagonist, was demonstrated after systemic (Kawamata et al. 2000; Holtman et al. 2008) or local application (Lawand et al. 1997; Romero et al. 2011).

The present study suggests that NOS modulates the antinociceptive effect of MK-801. As it is known that MK-801 is a non-competitive NMDA receptor antagonist, its antinociceptive effect observed in the present study might be the result of NMDA receptor antagonism. If the NMDA receptors that are blocked by MK- 801 are also linked to NO synthesis and release, then it is reasonable to predict that NOS inhibition in the central nervous system enhances the analgesia produced by MK-801 (Kawabata et al. 1994). However, in the present study, systemic administration of L-NAME reduced rather than enhanced the antinociceptive effect of MK-801. Also, our findings revealed that a selective nNOS inhibitor (L-NPA) or iNOS inhibitor (SMT) increased or reduced the effect of MK-801, respectively. These results are in partial agreement with our earlier results obtained with magnesium sulfate, also a noncompetitive NMDA receptor antagonist, which was tested under the same conditions (Srebro et al. 2014). The only difference between MK-801 and magnesium sulfate was that L-NPA reduced rather than increased the effect of magnesium sulfate. This discrepancy may be explained by the fact that, depending on $\mathrm{NO}$ concentration and the presence of NOS isoforms, NO can exert dual effects on redox balance and functions of neuron subpopulations (Kawabata et al. 1994; Zhang et al. 2006). The majority of data suggest a pronociceptive role of $\mathrm{NO}$ at the spinal level (Boettger et al. 2007; Schmidtko et al. 2009), while some studies indicate that NO is analgesic in the periphery in the early stage of inflammatory pain (Hamza et al. 2010). In general, inappropriate or excessive NO produced by iNOS and/or nNOS is associated with inflammatory and neuropathic pain (Payne et al. 2010). In addition, NOS inhibitors can exert both excitatory and inhibitory effects on NMDA-receptorassociated events (Dawson et al. 1991). Our findings indicate that L-NPA, an inhibitor of nNOS, increased MK-801induced analgesic effects in the carrageenan-induced peripheral hyperalgesia, suggesting that this NOS inhibitor increases the NMDA blockade produced by the action of the NMDA antagonist. Also, it was previously shown that the selective inhibitor of nNOS potentiated the antidepressant-like effect of MK-801 (Dhir and Kulkarni 2008). Increased expression of nNOS and/or iNOS has been shown in the lumbar spinal cord of rats after carrageenan injection into the hind paw (Chu et al. 2005). The levels of endothelial NOS (eNOS) in the spinal cord have been shown to remain unchanged in neurons after the injection of carrageenan (Tao et al. 2004). In CFA-monoarthritic rats, the intrathecal administration of ketamine produced a decrease in nNOS and increases in iNOS and eNOS expression in the dorsal horns (Infante et al. 2007). The explanation provided by the authors was that compensatory interactions influenced the expression of the different NOS isoforms. It has been pointed out that nNOS inhibitors could activate $\mathrm{NF}-\kappa \mathrm{B}$ (nuclear factor kappa-light-chain-enhancer of activated B cells) and iNOS (Togashi et al. 1997; O’Mahony and Kendall 1999) through upregulation iNOS genes (Xie et al. 1993). In this regard, we speculate that MK-801 decreased nNOS expression, and that this was related to the increased effect of L-NPA, a selective nNOS inhibitor, and SMT, a selective iNOS inhibitor, that reduced the antinoci- 
ceptive effect of MK-801. Taken together, the results of the present study indicate that the different effects of the inhibitors may be a consequence of a different impact of the NOS isoforms on the hyperalgesia, as well as interaction between MK-801 and NOS isoform(s).

Our results are in agreement with the previous report that treatment with SMT attenuated mechanical and heat hyperalgesia induced with monosodium iodoacetate (More et al. 2013). In addition, it has been shown that other selective inhibitors of iNOS, such as N-(3-(aminomethyl)benzyl) acetamidine $(1400 \mathrm{~W})$, reduce pain in carrageenan- or formalin-treated rats, while the neural inhibitor had no effect in either model (Tang et al. 2007). Also, (S)-2-amino-7acetamidino-5-thioheptanoic acid (GW274150), a selective inhibitor of iNOS, reduced CFA-induced mechanical hyperalgesia (De Alba et al. 2006).

In conclusion, the presented results suggest that systemic and local administration of MK-801 produce an antihyperalgesic effect in the carrageenan-induced inflammatory pain model in rats, and that the NOS modulates the effect of MK-801. Using MK-801 as a research tool, we have demonstrated the involvement of the NMDA receptors in the evolution of carrageenan-induced hyperalgesia and their interaction with NOS system, which may have an impact on the search for new approaches to pain management.

\section{Acknowledgments}

Work supported by the Ministry of Education, Science and Technological Development of Serbia (Grant No. 175023).

\section{Conflict of Interest}

The authors declare no conflict of interest.

\section{References}

Andreasen, J.T., Bach, A., Gynther, M., Nasser, A., Mogensen, J., Strømgaard, K. \& Pickering, D.S. (2013) UCCB01-125, a dimeric inhibitor of PSD-95, reduces inflammatory pain without disrupting cognitive or motor performance: comparison with the NMDA receptor antagonist MK-801. Neuropharmacology, 67, 193-200.

Begon, S., Pickering, G., Eschalier, A. \& Dubray, C. (2000) Magnesium and MK-801 have a similar effect in two experimental models of neuropathic pain. Brain Res., 887, 436-439.

Berrino, L., Oliva, P., Massimo, F., Aurilio, C., Maione, S., Grella, A. \& Rossi, F. (2003) Antinociceptive effect in mice of intraperitoneal N-methyl-D-aspartate receptor antagonists in the formalin test. Eur. J. Pain, 7, 131-137.

Boettger, M.K., Uceyler, N., Zelenka, M., Schmitt, A., Reif, A., Chen, Y. \& Sommer, C. (2007) Differences in inflammatory pain in nNOS-, iNOS- and eNOS-deficient mice. Eur. J. Pain, 11, 810-818.

Boyce, S., Wyatt, A., Webb, J.K., O’Donnell, R., Mason, G., Rigby, M., Sirinathsinghji, D., Hill, R.G. \& Rupniak, N.M. (1999) Selective NMDA NR2B antagonists induce antinociception without motor dysfunction: correlation with restricted localisation of NR2B subunit in dorsal horn. Neuropharmacology, 38, 611-623.

Calabrese, V., Mancuso, C., Calvani, M., Rizzarelli, E., Butterfield, D.A. \& Stella, A.M. (2007) Nitric oxide in the central nervous system: neuroprotection versus neurotoxicity. Nat. Rev. Neurosci., 8, 766-775.

Carey, R.J., Dai, H. \& Gui, J. (1998) Effects of dizocilpine (MK-801) on motor activity and memory. Psychopharmacology (Berl), 137, 241-246.

Cavalcante, A.L., Siqueira, R.M., Araujo, J.C., Gondim, D.V., Ribeiro, R.A., Quetz, J.S., Havt, A., Lima, A.A. \& Vale, M.L. (2013) Role of NMDA receptors in the trigeminal pathway, and the modulatory effect of magnesium in a model of rat temporomandibular joint arthritis. Eur. J. Oral Sci., 121, 573-583.

Chen, Z., Muscoli, C., Doyle, T., Bryant, L., Cuzzocrea, S., Mollace, V., Mastroianni, R., Masini, E. \& Salvemini, D. (2010) NMDA-receptor activation and nitroxidative regulation of the glutamatergic pathway during nociceptive processing. Pain, 149, 100-106.

Chu, Y.C., Guan, Y., Skinner, J., Raja, S.N., Johns, R.A. \& Tao, Y.X. (2005) Effect of genetic knockout or pharmacologic inhibition of neuronal nitric oxide synthase on complete Freund's adjuvant-induced persistent pain. Pain, 119, 113-123.

Davidson, E.M., Coggeshall, R.E. \& Carlton, S.M. (1997) Peripheral NMDA and non-NMDA glutamate receptors contribute to nociceptive behaviors in the rat formalin test. Neuroreport, $\mathbf{8}$, 941-946.

Dawson, V.L., Dawson, T.M., London, E.D., Bredt, D.S. \& Snyder, S.H. (1991) Nitric oxide mediates glutamate neurotoxicity in primary cortical cultures. Proc. Natl. Acad. Sci. USA, 15, 6368-6371.

De Alba, J., Clayton, N.M., Collins, S.D., Colthup, P., Chessell, I. \& Knowles, R.G. (2006) GW274150, a novel and highly selective inhibitor of the inducible isoform of nitric oxide synthase (iNOS), shows analgesic effects in rat models of inflammatory and neuropathic pain. Pain, 120, 170-181.

Dhir, A. \& Kulkarni, S.K. (2008) Possible involvement of nitric oxide (NO) signaling pathway in the antidepressant-like effect of MK-801(dizocilpine), a NMDA receptor antagonist in mouse forced swim test. Indian J. Exp. Biol., 46, 164-170.

Du, J., Zhou, S., Coggeshall, R.E. \& Carlton, S.M. (2003) $\mathrm{N}$-methyl-D-aspartate-induced excitation and sensitization of normal and inflamed nociceptors. Neuroscience, 118, 547-562.

Freire, M.A. (2012) Pathophysiology of neurodegeneration following traumatic brain injury. West Indian Med. J., 61, 751-755.

Freire, M.A., Guimarães, J.S., Leal, W.G. \& Pereira, A. (2009) Pain modulation by nitric oxide in the spinal cord. Front. Neurosci., 3, 175-181.

Gong, N., Gao, Z.Y., Wang, Y.C., Li, X.Y., Huang, J.L., Hashimoto, K. \& Wang, Y.X. (2011) A series of D-amino acid oxidase inhibitors specifically prevents and reverses formalin-induced tonic pain in rats. J. Pharmacol. Exp. Ther, 336, 282-293.

Hama, A., Woon Lee, J. \& Sagen, J. (2003) Differential efficacy of intrathecal NMDA receptor antagonists on inflammatory mechanical and thermal hyperalgesia in rats. Eur. J. Pharmacol., 459, 49-58.

Hamza, M., Wang, X.M., Wu, T., Brahim, J.S., Rowan, J.S. \& Dionne, R.A. (2010) Nitric oxide is negatively correlated to pain during acute inflammation. Mol. Pain, 6, 55.

Holtman, J.R. Jr., Crooks, P.A., Johnson-Hardy, J.K., Hojomat, M., Kleven, M. \& Wala, E.P. (2008) Effects of norketamine enantiomers in rodent models of persistent pain. Pharmacol. Biochem. Behav., 90, 676-685.

Im, D.S., Jeon, J.W., Lee, J.S., Won, S.J., Cho, S.I., Lee, Y.B. \& Gwag, B.J. (2012) Role of the NMDA receptor and iron on free radical production and brain damage following transient middle cerebral artery occlusion. Brain Res., 1455, 114-123.

Infante, C., Díaz, M., Hernández, A., Constandil, L. \& Pelissier, T. (2007) Expression of nitric oxide synthase isoforms in the 
dorsal horn of monoarthritic rats: effects of competitive and uncompetitive N-methyl-D-aspartate antagonists. Arthritis Res. Ther, 9, R53.

Jackson, D.L., Graff, C.B., Richardson, J.D. \& Hargreaves, K.M. (1995) Glutamate participates in the peripheral modulation of thermal hyperalgesia in rats. Eur. J. Pharmacol., 284, 321-325.

Jeong, H.Y., Kim, J.Y., Lee, H.K., Ha do, T., Song, K.S., Bae, K. \& Seong, Y.H. (2010) Leaf and stem of Vitis amurensis and its active components protect against amyloid $\beta$ protein (25-35)induced neurotoxicity. Arch. Pharm. Res., 33, 1655-1664.

Kawabata, A., Manabe, S., Manabe, Y. \& Takagi, H. (1994) Effect of topical administration of L-arginine on formalin-induced nociception in the mouse: a dual role of peripherally formed NO in pain modulation. Br. J. Pharmacol., 112, 547-550.

Kawamata, T. \& Omote, K. (1999) Activation of spinal N-methyl$\mathrm{D}$-aspartate receptors stimulates a nitric oxide/cyclic guanosine 3,5-monophosphate/glutamate release cascade in nociceptive signaling. Anesthesiology, 91, 1415-1424.

Kawamata, T., Omote, K., Sonoda, H., Kawamata, M. \& Namiki, A. (2000) Analgesic mechanisms of ketamine in the presence and absence of peripheral inflammation. Anesthesiology, 93, 520-528.

Kovacic, P. \& Somanathan, R. (2010) Clinical physiology and mechanism of dizocilpine (MK-801): electron transfer, radicals, redox metabolites and bioactivity. Oxid. Med. Cell. Longev., 3, 13-22.

Lawand, N.B., McNearney, T. \& Westlund, K.N. (2000) Amino acid release into the knee joint: key role in nociception and inflammation. Pain, 86, 69-74.

Lawand, N.B., Willis, W.D. \& Westlund, K.N. (1997) Excitatory amino acid receptor involvement in peripheral nociceptive transmission in rats. Eur. J. Pharmacol., 324, 169-177.

More, A.S., Kumari, R.R., Gupta, G., Lingaraju, M.C., Balaganur, V., Pathak, N.N., Kumar, D., Kumar, D., Sharma, A.K. \& Tandan, S.K. (2013) Effect of iNOS inhibitor S-methylisothiourea in monosodium iodoacetate-induced osteoathritic pain: implication for osteoarthritis therapy. Pharmacol. Biochem. Behav., 103, 764-772.

Olney, J.W., Labruyere, J. \& Price, M.T. (1989) Pathological changes induced in cerebrocortical neurons by phencyclidine and related drugs. Science, 244, 1360-1362.

O’Mahony, D. \& Kendall, M.J. (1999) Nitric oxide in acute ischaemic stroke: a target for neuroprotection. J. Neurol. Neurosurg. Psychiatry, 67, 1-3.

Payne, J.E., Bonnefous, C., Symons, K.T., Nguyen, P.M., Sablad, M., Rozenkrants, N., Zhang, Y., Wang, L., Yazdani, N., Shiau, A.K., Noble, S.A., Rix, P., Rao, T.S., Hassig, C.A. \& Smith, N.D. (2010) Discovery of dual inducible/neuronal nitric oxide synthase (iNOS/nNOS) inhibitor development candidate 4-((2-cyclobutyl-1H-imidazo[4,5-b]pyrazin-1-yl)methyl)7,8-difluoroquinolin-2(1H)-one (KD7332) part 2: identification of a novel, potent, and selective series of benzimidazolequinolinone iNOS/nNOS dimerization inhibitors that are orally active in pain models. J. Med. Chem., 53, 7739-7755.

Petrenko, A.B., Yamakura, T., Baba, H. \& Shimoji, K. (2003) The role of N-methyl-D-aspartate (NMDA) receptors in pain: a review. Anesth. Analg., 97, 1108-1116.

Ren, K., Hylden, J.L., Williams, G.M., Ruda, M.A. \& Dubner, R. (1992a) The effects of a non-competitive NMDA receptor antagonist, MK-801, on behavioral hyperalgesia and dorsal horn neuronal activity in rats with unilateral inflammation. Pain, 50, 331-344.

Ren, K., Williams, G.M., Hylden, J.L., Ruda, M.A. \& Dubner, R. (1992b) The intrathecal administration of excitatory amino acid receptor antagonists selectively attenuated carrageenaninduced behavioral hyperalgesia in rats. Eur. J. Pharmacol., 219, 235-243.
Romero, T.R., Galdino, G.S., Silva, G.C., Resende, L.C., Perez, A.C., Côrtes, S.F. \& Duarte, I.D. (2011) Ketamine activates the L-arginine/Nitric oxide/cyclic guanosine monophosphate pathway to induce peripheral antinociception in rats. Anesth. Analg., 113, 1254-1259.

Rung, J.P., Carlsson, A., Rydén Markinhuhta, K. \& Carlsson, M.L. (2005) (+)-MK-801 induced social withdrawal in rats; a model for negative symptoms of schizophrenia. Prog. Neuropsychopharmacol. Biol. Psychiatry, 29, 827-832.

Schmidtko, A., Tegeder, I. \& Geisslinger, G. (2009) No NO, no pain? The role of nitric oxide and cGMP in spinal pain processing. Trends Neurosci., 32, 339-346.

Srebro, D.P., Vučković, S., Vujović, K.S. \& Prostran, M. (2014) Anti-hyperalgesic effect of systemic magnesium sulfate in carrageenan-induced inflammatory pain in rats: influence of the nitric oxide pathway. Magnes. Res., 27, 77-85.

Suetake-Koga, S., Shimazaki, T., Takamori, K., Chaki, S., Kanuma, K., Sekiguchi, Y., Suzuki, T., Kikuchi, T., Matsui, Y. \& Honda, T. (2006) In vitro and antinociceptive profile of HON0001, an orally active NMDA receptor NR2B subunit antagonist. Pharmacol. Biochem. Behav., 84, 134-141.

Tanabe, M., Nagatani, Y., Saitoh, K., Takasu, K. \& Ono, H. (2009) Pharmacological assessments of nitric oxide synthase isoforms and downstream diversity of NO signaling in the maintenance of thermal and mechanical hypersensitivity after peripheral nerve injury in mice. Neuropharmacology, 56, 702-708.

Tang, Q., Svensson, C.I., Fitzsimmons, B., Webb, M., Yaksh, T.L. \& Hua, X.Y. (2007) Inhibition of spinal constitutive NOS-2 by $1400 \mathrm{~W}$ attenuates tissue injury and inflammation-induced hyperalgesia and spinal p38 activation. Eur. J. Neurosci., 25, 2964-2972.

Tao, F., Tao, Y.X., Zhao, C., Dore, S., Liaw, W.J., Raja, S.N. \& Johns, R.A. (2004) Differential roles of neuronal and endothelial nitric oxide synthases during carrageenan-induced inflammatory hyperalgesia. Neuroscience, 128, 421-430.

Togashi, H., Sasaki, M., Frohman, E., Taira, E., Ratan, R.R., Dawson, T.M. \& Dawson, V.L. (1997) Neuronal (type I) nitric oxide synthase regulates nuclear factor $\kappa \mathrm{B}$ activity and immunologic (type II) nitric oxide synthase expression. Proc. Natl. Acad. Sci. USA, 94, 2676-2680.

Vaccarino, A.L., Marek, P., Kest, B., Weber, E., Keana, J.F. \& Liebeskind, J.C. (1993) NMDA receptor antagonists, MK-801 and ACEA-1011, prevent the development of tonic pain following subcutaneous formalin. Brain Res., 615, 331-334.

Vezzani, A., Serafini, R., Stasi, M.A., Caccia, S., Conti, I., Tridico, R.V. \& Samanin, R. (1989) Kinetics of MK-801 and its effect on quinolinic acid-induced seizures and neurotoxicity in rats. J. Pharmacol. Exp. Ther., 249, 278-283.

Wang, Q., Li, J., Wei, X., Liao, J., Xu, Y., Lu, T., Qin, B., Xie, J., Deng, C. \& Huang, X. (2014) Alterations of NMDA receptor binding in various brain regions among 6-hydroxydopamineinduced Parkinsonian rats. Int. J. Neurosci., 124, 457-465.

Xie, Q.W., Whisnant, R. \& Nathan, C. (1993) Promoter of the mouse gene encoding calcium-independent nitric oxide synthase confers inducibility by interferon gamma and bacterial lipopolysaccharide. J. Exp. Med., 177, 1779-1784.

Yamamoto, T. \& Yaksh, T.L. (1992) Comparison of the antinociceptive effects of pre- and posttreatment with intrathecal morphine and MK801, an NMDA antagonist, on the formalin test in the rat. Anesthesiology, 77, 757-763.

Yonehara, N., Amano, K. \& Kamisaki, Y. (2002) Involvement of the NMDA-nitric oxide pathway in the development of hypersensitivity to tactile stimulation in dental injured rats. Jpn. J. Pharmacol., 90, 145-155.

Zhang, X.C., Zhang, Y.Q. \& Zhao, Z.Q. (2006) Different roles of two nitric oxide activated pathways in spinal long-term potentiation of C-fiber-evoked field potentials. Neuropharmacology, 50, 748-754. 